\title{
LA CONFORMACIÓN DE UNA TRAMA COLECTIVA DE PUBLICACIONES CULTURALES SUBTERRÁNEAS DURANTE LA ÚLTIMA DICTADURA CÍVICO-MILITAR ARGENTINA
}

\author{
EVANGELINA MARGIOLAKIS (UBA) \\ Instituto de Investigaciones Gino Germani \\ Facultad de Ciencias Sociales \\ Universidad de Buenos Aires \\ emargiolakis@gmail.com
}

\section{Resumen:}

El trabajo se propone describir el rol de publicaciones culturales subterráneas o underground durante la última dictadura cívico- militar argentina (1976-1983). Surgidas en contextos represivos, ellas indagaron temáticas invisibilizadas en otros espacios y conformaron redes de articulación de colectivos de publicaciones. Asimismo, dichas publicaciones desafiaron los límites impuestos por el poder hegemónico militar en relación con su propuesta de intervención político-cultural, su ubicación en el mercado de los bienes simbólicos y el rescate de tradiciones diferentes a aquellas recuperadas por la denominada "cultura oficial".

Se intentará analizar el lugar que ocuparon las diferentes revistas en relación con el modo de abordaje temático, su propuesta estética y sus condiciones de producción y circulación.

\section{Palabras Clave:}

Periodismo Cultural - Prensa Subterránea - Dictadura Militar - Formación Cultural

\begin{abstract}
:
This work proposes to describe the role of underground cultural magazines during the last argentine civic-military dictatorship (1976-1983). Emerged in repressive contexts, they investigated topics which were invisible in other spaces and shaped networks of articulation of collective publications. These magazines also challenged the limits imposed by hegemonic military power in relation to their proposal of politic and cultural intervention, their location in the market of simbolic properties and the rescue of traditions which were different from those which were rescued by the denominated "oficial culture".

We intend to analyze the place which the different magazines occupied in relation to their thematic approach, their esthetical proposal and their production and circulation conditions.
\end{abstract}

\section{Keywords:}

Cultural Journalism - Underground Press - Military Dictatorship - Cultural Formation 


\title{
LA CONFORMACIÓN DE UNA TRAMA COLECTIVA DE PUBLICACIONES CULTURALES SUBTERRÁNEAS DURANTE LA ÚLTIMA DICTADURA CÍVICO-MILITAR ARGENTINA
}

\author{
EVANGELINA MARGIOLAKIS (UBA)
}

emargiolakis@gmail.com

\section{Introducción: Antecedentes de lo underground y lo alternativo}

El Terrorismo de Estado implantado en Argentina a partir del golpe militar de 1976 produjo la instauración de un plan sistemático de censura, represión y desaparición forzosa de personas. En el plano simbólico, tales dispositivos no fueron ajenos sino que un conjunto de políticas culturales emanadas del régimen militar desplegaron estrategias tendientes a promover la censura, la autocensura y la represión, aunque ellas no se llevaron a cabo en forma uniforme. La dinámica de funcionamiento de esta esfera revela la coexistencia, junto a estos mecanismos represivos y de control, de una serie de prácticas -variadas y heterogéneas- que surgieron al margen, en los bordes o desafiando en algún aspecto estos mecanismos. En este marco, un conjunto de revistas culturales denominadas subterráneas o underground subsistieron o surgieron con el fin de recuperar la necesidad de expresión y poner en palabras aquello que no podía circular en otros ámbitos. De esta manera, se fue conformando una red de publicaciones de carácter contracultural, en las que diferentes grupos participaron generando lazos de cooperación y solidaridad. En contraposición a la idea que la dictadura implicó un proceso de silenciamiento, encierro o autorrepliegue, estas publicaciones demostraron el dinamismo que adquirió esta zona del campo cultural. ${ }^{1}$

Respecto de sus antecedentes, la denominación "prensa subterránea" refiere a aquellos medios que surgieron como respuesta a dispositivos de disciplinamiento. En América Latina, las revistas subterráneas irrumpieron en la década de 1960, en el marco de procesos dictatoriales y represivos. Debido a la imposición de mecanismos de censura, estas experiencias se gestaron como respuesta a la necesidad de expresión y cuestionamiento de lo establecido. Durante la última dictadura argentina (1976-1983) lo underground no necesariamente implicó clandestinidad sino que remitió a una postura de disidencia respecto del poder hegemónico militar. Mientras que ciertas publicaciones se hicieron eco del canon oficial y replicaron el discurso dominante, estas revistas rescataron tradiciones diferentes, cuestionaron la cultura oficial y recuperaron otros "modos de decir", tendientes a cuestionar la represión y el autoritarismo.

Nos proponemos trazar un panorama general de las diferentes publicaciones que conformaron este universo de experiencias, que fueron también caracterizadas el rótulo de "prensa alternativa". El concepto de alternatividad comenzó a utilizarse en América Latina hacia la década de 1970, tomando impulso en la década siguiente. Refiere a "otro" modelo de comunicación diferente al

\footnotetext{
${ }^{1}$ Un acercamiento a este tipo de revistas se encuentra desarrollado en el trabajo de Cecily Marcus. Para mayor información, léase: Marcus, Cecily, "En la Biblioteca Vaginal: un Discurso Amoroso" en: Políticas de la memoria $\mathrm{N}^{\circ}$ 6/7, CeDInCI, Primavera 2006-2007.
} 
de los medios masivos comerciales, representantes de la cultura dominante. Lo alternativo ${ }^{2}$ considera el acceso igualitario, la participación en la producción de mensajes y la toma de decisiones colectiva con la finalidad de dar voz a grupos relegados de la sociedad y recuperar la posibilidad de tomar la palabra desde otro lugar.

En nuestro caso analizado, las revistas subterráneas o alternativas -conceptos que fueron utilizados indistintamente- se propusieron dar voz a quienes no tenían lugar en los grandes medios y, a su vez, surgieron como necesidad de expresión de grupos culturales de jóvenes con inquietudes que propusieron una jerarquización y tratamiento temático diferente al de aquellos medios que representaron la vOz de la cultura oficial, indagando en la experimentación de "otros" modos de narrar.

\section{E1 rol de los grupos culturales}

Las publicaciones que son objeto de nuestro estudio ${ }^{3}$ se configuraron como órganos de difusión de ideas provenientes de grupos culturales o formaciones ${ }^{4}$ que le dieron origen.

De esta manera, diferentes grupos encontraron un espacio de intercambio y puesta en común de inquietudes. Si bien las publicaciones se ligan a agrupamientos de jóvenes, también podían estar presentes actores reconocidos en el campo cultural. ${ }^{5}$ Lo grupal entonces, implicó la posibilidad de pertenecer a un proyecto común a partir del interés por la música, el cuento o la poesía y de crear un espacio de expresión y contención en un contexto en el que se desplegaban mecanismos de atomización y de ruptura del lazo social.

Asimismo, para estos productores culturales nucleados alrededor de revistas, lo simbólico fue un lugar estratégico para la concreción de proyectos y la intervención cultural fue concebida como la posibilidad de desarrollar tácticas de "creación". Desde la percepción de sus protagonistas, quienes observan retrospectivamente estas diversas experiencias ${ }^{6}$, la posibilidad de participar en un proyecto a partir de objetivos comunes implicó la búsqueda de algo distinto. En todos los casos, el periodismo literario fue concebido como una forma de expresión "creadora" diferente, como un gesto de rebeldía, como un impulso vital y un rescate de la libertad.

La relevancia otorgada a la posibilidad de expresar aquello que se encontraba ausente en otros ámbitos fue un rasgo distintivo en este tipo de publicaciones. Lo cultural y las palabras encontraron un lugar para experimentar y desafiar los límites, dando paulatinamente visibilidad -a diferencia de otros medios que representaban la cultura oficial- a ciertos problemas y polémicas, como la crítica a la censura, la oposición al enfrentamiento con Chile por el Canal de Beagle, el

\footnotetext{
2 Máximo Simpson Grinberg enuncia una serie de problematizaciones acerca del concepto de comunicación alternativa, estudiando su incidencia en los procesos latinoamericanos. En: Simpson Grinberg, Máximo, Comunicación alternativa y cambio social, México, Premia, 1986.

3 Algunas de las publicaciones mencionadas se encuentran digitalizadas y disponibles en www.archivosenuso.org

4 Raymond Williams caracteriza las formaciones culturales como movimientos y tendencias efectivos en la vida intelectual y artística. Se trata de formas de organización o autoorganización más informales vinculadas con la producción cultural que se diferencian -siendo esta relación variable- de las instituciones, que poseen reglas más perdurables y duraderas. Cf. Williams, Raymond, Marxismo y Literatura, Barcelona, Península, 1988; Williams, Raymond, Cultura. Sociología de la Comunicación y del Arte, Barcelona, Paidós, 1994.

${ }^{5}$ Un ejemplo de actor reconocido y con trayectoria en el campo del periodismo cultural es el caso de Abelardo Castillo, fundador de El Ornitorrinco en 1977, quien ya había participado como director en los proyectos editoriales de El Grillo de Papel y El escarabajo de Oro durante la década de 1960.

${ }^{6}$ A lo largo de la investigación se han realizado una serie de entrevistas a distintos miembros de publicaciones, las que permitieron trazar algunos ejes de análisis e interpretación que se esbozan en el artículo.
} 
acompañamiento a los reclamos de organismos de Derechos Humanos que denunciaban la desaparición de personas y el cuestionamiento a la guerra de Malvinas, entre otros tópicos.

\section{Confluencia de tradiciones diferentes}

Intentaremos presentar diferentes revistas que conformaron este universo de publicaciones de carácter contracultural. Se trata de diferentes publicaciones surgidas en la Ciudad de Buenos Aires y el conurbano bonaerense. No pretendemos incluir todas las experiencias sino ubicar posiciones reconstruidas a partir del análisis de condiciones de producción y circulación, tópicos de discusión y tradiciones rescatadas.

\section{La tradición del underground y la cultura beat: Antimitomanía}

La revista Antimitomanía constituye un antecedente de aquellas revistas que, surgidas en momentos previos, perduraron durante la dictadura ${ }^{7}$. Uno de sus elementos distintivos consistió en el rescate de la tradición del underground vinculado a la cultura beat norteamericana. Por esta razón, se reconocía en el legado de revistas que rescataron incipientemente en nuestro país esta tradición, las que formaron parte de los proyectos editoriales de Miguel Grinberg durante las décadas de 1960 y 1970 respectivamente, como han sido los casos de Contracultura y Eco Contemporáneo. Antimitomanía, editada en el noroeste del conurbano bonaerense -en las localidades de Bella Vista y San Miguel-, retomaba la cultura hippie y la filosofía orientalista, surgidas en Estados Unidos a fines de la década de 1950.

De esta manera, desde la publicación se proponía un tipo de transformación basado en la no violencia y la crítica a la sociedad de consumo. En este sentido, se destacaba la figura de Adolfo Pérez Esquivel en el Servicio de Paz y Justicia (SERPAJ) ${ }^{8}$ y el modelo de intervención intelectual de Mahatma Gandhi como exponentes del diálogo y la paz. Asimismo, tenían espacio escritores norteamericanos como Thomas Merton, Allen Ginsberg y Jack Kerouac, representantes de esta tradición.

En sus páginas, ocupaba un gran espacio la poesía, los poetas místicos -ya que ponían en juego la experiencia espiritual-, la música del denominado rock nacional y la poesía vital latinoamericana. Asimismo, se publicaba el suplemento Uvas Nuevas, dedicado a compilar antologías de poemas. Alrededor de la revista se realizaron encuentros y recitales de poesía y música, por ejemplo, en el Centro de Estudio de San Miguel. Por lo tanto, uno de los rasgos distintivos de Antimitomanía consistió en la valorización de la tradición del underground norteamericano, a partir de la presencia lecturas, usos y apropiaciones de sus referentes y del intercambio con ellos a partir de cartas o de la difusión y análisis de sus obras.

\section{El compromiso sartreano en E1 Ornitorrinco}

El Ornitorrinco, surgida en 1977 y dirigida por Abelardo Castillo, conforma un caso relevante para comprender la necesidad de refundar ciertas publicaciones a partir de reconocer que las condiciones de producción y circulación habían cambiado abruptamente a partir del golpe de

\footnotetext{
${ }^{7}$ Dirigida por Daniel Serra, la revista surge en 1974 (primera época) y luego reconoce una segunda época a partir de 1979 , según consta en sus ediciones.

${ }^{8}$ La revista publicaba una nota denominada "Diálogo real", analizando las repercusiones y opiniones suscitadas en Argentina y el exterior a partir de la entrega del Premio Nobel de la Paz a Adolfo Pérez Esquivel. En: Antimitomanía $\mathrm{N}^{\circ} 17$, Primavera de 1981.
} 
1976. Si bien los proyectos de Castillo datan de décadas anteriores con la edición de El Escarabajo de Oro y El grillo de Papel, el grupo que nucleó a esta nueva publicación percibió la necesidad de seguir editando una revista aunque bajo otro nombre. El Ornitorrinco surgió entonces como un nuevo "animal" que mezclaba diversos rasgos de seres vivientes, de la misma manera que en la revista confluyeron actores con diferentes perspectivas, a diferencia de la menor diversidad entre sus miembros que había existido en las publicaciones que constituyeron sus antecedentes. Para Castillo, la heterogeneidad del grupo editor guardó estrecha relación con el contexto. Aquello que no hubiera sido posible de nuclear en otro momento histórico, tomaba forma bajo la dictadura a partir de la necesidad de confluencia de sus integrantes que, aunque diferentes, se reunían a partir de una publicación que estableció como principal propósito indagar en los límites no siempre fijos de la censura. ${ }^{9}$

Una característica central de la publicación es que, al igual que sus antecesoras, la revista fue caracterizada como publicación sartreana. El rescate de Sartre se hacía evidente en la idea de intelectual comprometido con los procesos de su tiempo así como en la recuperación de la "libertad vital". En su primera editorial, la revista concebía el arte de escribir como un acto a favor de la vida. De esta manera, el énfasis estuvo puesto en dar paso a la libertad de las palabras.

En sus ediciones se rescató la lingüística y la semiología y tuvieron espacio jóvenes escritores. Así, lo nuevo convivía con el rescate de autores reconocidos como César Vallejo y Olga Orozco.

Un eje de discusión que tuvo visibilidad en la revista fue la polémica alrededor del exilio, en la que sus miembros, que se reconocían entre quienes habían optado por "quedarse", discutieron con la idea de que sólo era posible producir en el exilio:

"Este es nuestro país, tanto como el de cualquier otro argentino, esta es la única Historia que vamos a vivir. Hemos elegido vivirla desde adentro, no desde París o Roma. El exilio y el silencio son la muerte espiritual de un escritor: estamos acá y lo único que tenemos son palabras. Que es como decir que tenemos la suerte de estar vivos". ${ }^{10}$

En abierta confrontación con aquellos intelectuales que desde el exilio caracterizaban el campo cultural local como un espacio de silencio, aislamiento e inacción, la respuesta de la revista consistió en rescatar la experiencia propia y de otras publicaciones que hicieron uso de las palabras como herramienta y recurso "vital". Quienes no habían optado por el exilio manifestaban que tenían "algo para decir" desde el impulso de estar vivos.

A inicios de 1981, la revista fue uno de los pocos medios que reprodujo la solicitada que reclamaba la publicación de las listas de desaparecidos y la información sobre el paradero de los mismos. Tanto desde las palabras como desde el recurso del humor gráfico, El Ornitorrinco se propuso desafiar los límites impuestos por el poder hegemónico recurriendo a metáforas, alegorías y recursos satíricos e irónicos.

\section{El rescate del surrealismo en Poddema y Signo Ascendente}

Otro conjunto de publicaciones lo constituyen aquellas revistas que rescataron la tradición surrealista y sus referentes tanto europeos como aquellos que retomaron las ideas del movimiento en América Latina y Argentina. Es el caso de Poddema, creada en 1979 y editada luego con el

\footnotetext{
${ }^{9}$ Un análisis de la revista se encuentra en Iglesias, Federico, "Vale más revista literaria en mano que escritor volando: El Ornitorrinco y el rol de los escritores durante la última dictadura cívico militar argentina, 1976-1983”, ponencia ante las Terceras Jornadas de Investigación del AGU, Montevideo, Uruguay, 2013.

${ }^{10}$ Castillo, Abelardo, "Editorial: La década vacía”, en El Ornitorrinco Nº 6ulio-agosto de 1979, p. 3.
} 
nombre de Signo Ascendente. El primer número surgía a partir de la iniciativa de su director, Alberto Valdivia y desde su segundo número, se trató de un proyecto editorial colectivo en el que tuvo protagonismo un grupo de estudio sobre el surrealismo conformado por estudiantes de Letras.

Además de la presencia de grupos de estudio que concibieron las revistas como órganos de difusión de sus ideas, la existencia de estas publicaciones permite observar el sentido particular que adquirió la recuperación de un movimiento histórico de vanguardia surgido en el contexto europeo y cuyas ideas-fuerza fueron retomadas décadas después en el marco de un régimen dictatorial.

En este sentido, un rasgo importante lo conformó la relevancia otorgada a la esfera del inconsciente, comprendida como aquella que permitiría sacar a la luz lo que no era posible de visualizar a primera vista. La revista rescataba el inconsciente como espacio de liberación de las represiones:

"Si debiéramos recurrir a pocas palabras para expresar claramente nuestra realidad como órgano de difusión de unas ideas que consideramos de las más importantes, nos quedaríamos sin duda con esas que André Breton lanza, dados cargados de luz, apenas la luz de su libro 'La llave de los campos' se abre: 'Lo que más necesidad tengo de decir no es, ni mucho menos, lo que mejor digo'. Del choque entre nuestros deseos y nuestras posibilidades, esperamos, más allá de lo previsto, darnos a conocer". ${ }^{11}$

La idea-fuerza se centraba en el rescate del deseo y el choque con la posibilidad de realizarlo. De esta manera, se manifestaba la tensión permanente entre la necesidad de expresión y creación por un lado, y sus condiciones de posibilidad y realización por el otro. Ese conflicto entre lo posible e imposible, lo probable y lo realizable, atravesó las diversas reflexiones de la revista.

En 1980, surgía Signo Ascendente (ex Poddema), exaltando la idea de un arte independiente, alejado de condicionamientos políticos. Haciendo una referencia más explícita al contexto imperante, se reflexionaba acerca de los límites de la censura Así aparecía en la primera editorial:

"Para el arte y los artistas, los límites impuestos significan trabajo perdido, años perdidos, empezar nuevamente, estar siempre en el comienzo, no avanzar, emigrar, etc. Por esto, la censura generalizada e impune significa años de atraso y no es sobre quienes hoy reclamamos la libertad de expresión que reacae la responsabilidad de ello."12

La libertad en el arte fue otro eje de jerarquización que recorrió las reflexiones de este órgano de difusión. El rescate de la esfera artística como espacio expresivo revelaba la tensión existente entre ese espíritu libertario y la imposición de mecanismos de censura. Por esta razón, Poddema concibió la vocación poética como espacio de libertad de creación y como vocación "vital" y de esta manera, el arte fue comprendido como la posibilidad de desarrollar mayor conciencia. Hacer más arte implicaba para estas publicaciones la posibilidad de hacer más concientes las condiciones de producción de esa literatura.

\section{Revistas vinculadas a la tradición de partidos políticos de izquierda: Nudos y Propuesta}

Otra zona posible de delimitar es aquella conformada por publicaciones que formaron parte de la tradición de partidos de izquierda, a pesar de que el vínculo con las agrupaciones políticas no fuera orgánico debido al contexto imperante. Es el caso de Nudos, vinculada al PCR (Partido

11 "Entrada" en: Revista Poddema $\mathrm{N}^{\circ} 2$, febrero de 1980, p. 1.

12 "Por un arte independiente" en Revista Signo Ascendente N 1, octubre de 1980, p. 3. 
Comunista Revolucionario) y Propuesta, vinculada al PST (Partido Socialista de los Trabajadores). Debido al vínculo mencionado y a la existencia de dispositivos de disciplinamiento y control, algunos de los editores de estas publicaciones recurrieron al uso de seudónimos.

En 1978, se publicaba Nudos, dirigida por Manuel Amigo y Jorge Brega, quienes habían participado en la edición de la revista Los Libros anteriormente. Nudos recuperó la tradición del maoísmo a partir del rescate de autores y obras vinculadas con la creación de una cultura nacional y popular. Por ello la presencia de reflexiones acerca del teatro independiente, la Campaña del desierto leída e interpretada desde "las tierras del indio", la historia del carnaval en la Boca, la estética de la cantante mapuche Aimé Painé, el grabado popular y la pintura campesina china. Un lugar importante en esta publicación lo ocuparon las imágenes, se trate de ilustraciones o de la exhibición de numerosas trabajos de actores del campo artístico como Víctor Grippo o Aída Carballo, quien también fuera una colaboradora permanente en la publicación.

Asimismo, es importante destacar el trabajo de su director, Manuel Amigo, quien desde su intervención plástica, exhibida en galerías de Buenos Aires y reproducida en la revista, hizo referencia a la ausencia de seres queridos. Su serie "Objetos" (1978) se centraba en la desaparición forzosa de personas a partir de elementos de uso doméstico en desuso, pintados con tonalidades grises y recubiertos con materiales que brindaron a los objetos un aspecto fósil y a la vez, acomodados como ofrendas o altares callejeros. En 1980, se reprodujeron en la revista imágenes de esta obra de Amigo, quien reflexionaba sobre su serie a partir de una entrevista:

"Los bultos, los paquetes abandonados, han obsesionado a muchos artistas por lo siniestro de la imagen. El que yo utilice zapatos y otras prendas que alguien ha vestido, es porque tienen un poder de perpetuar presencias que yo utilizo con un sentido preciso. (...) Ese es el tipo de drama que deseo transmitir. ¿Dónde está el hombre que tenía los zapatos puestos? ¿Dónde están las personas que vestían estas prendas que aún transmiten su presencia?". ${ }^{13}$

Como recurso retórico, la elipsis que operaba a partir de imágenes y palabras, intentaba evocar la figura de los desaparecidos por el Terrorismo de Estado. De este modo, la intervención en el espacio simbólico fue un modo de intervención política en esta publicación.

Por su parte, la revista Propuesta surgía en 1978 como inquietud de un grupo de jóvenes de Quilmes y la zona Sur del conurbano bonaerense. Si bien sólo algunos de sus integrantes se encontraban vinculados con el Partido Socialista de los Trabajadores, ciertas preocupaciones referían a cuestiones abordadas por la tradición trotskista, la que en el plano cultural y estético asumía como legado el encuentro entre Breton y Trotsky. De esta manera, se jerarquizaron temáticas como la problemática del cuerpo, el teatro experimental y el lugar de la mujer. Desde la mirada de sus protagonistas, los primeros cinco números permiten ubicar a la revista en la zona de lo "subte". Luego la revista experimentó algunos desplazamientos y comenzó a tener una línea editorial que fue girando lentamente hacia una revista que incluía otras zonas como la sociología, la crítica cultural de medios y la política. Fue así como el último número, inédito, incluía una nota sobre la revolución iraní.

Además de la revista como órgano de expresión, el grupo cultural nucleado a partir de la publicación, organizó recitales ${ }^{14}$ y charlas de divulgación. Fue muy importante el espacio asignado al cine nacional, el teatro y el rock. Sus notas abordaban tanto lo novedoso como reportajes a figuras ya consagradas o reconocidas como Federico Luppi o Caloi. Es interesante advertir los

13 "Manuel Amigo" en Revista Nudos No 7, julio de 1980, p. 14.

${ }^{14}$ La revista organizó el Festival de la Primavera en Racing, un recital de rock en el que participaron figuras como Juan Carlos Baglietto. 
vínculos entre lo personal y lo político, donde la idea de pertenencia, en este caso, a una publicación, excedía los límites de la publicación misma. Desde la percepción de sus protagonistas, la revista fue una más de las tantas experiencias antidictatoriales y de rebeldía juvenil.

\section{La nueva izquierda en Ulises y Sitio}

En esta zona ubicamos dos publicaciones que discutieron con ciertas dicotomías como el esteticismo en oposición al realismo y rescataron perspectivas como el psicoanálisis y la antropología. Tales publicaciones inauguraron una serie de tópicos de discusión innovadores y críticos respecto del programa cultural de los partidos políticos de izquierda tradicionales, incorporando nuevos elementos y ejes para el debate. ${ }^{15}$

En abril de 1978, se creaba Ulises $^{16}$. En su primera editorial, se proponía cubrir una necesidad, llenar un vacío y contribuir a nuevas formas expresivas que permitieran manifestarse a las nuevas generaciones de escritores sin restringir su capacidad creativa.

En clara polémica con el realismo, por un lado, y con las expresiones del "arte por el arte", por el otro, proponía un tipo de literatura que fuera al encuentro de nuevas estéticas, articulando o poniendo en tensión ambas tendencias. Es decir, se proponía indagar en nuevas formas que tendieran a superar dialécticamente las tradiciones vinculadas al esteticismo en oposición a aquellas vinculadas al realismo:

"Ulises repudia y denuncia los subproductos artísticos calentados -como decía Castelar- en las estufas académicas, las expresiones decadentistas y aristocratizantes de quienes proclaman el arte por el arte o el estrecho realismo de los que quieren hacer del arte una didáctica de la revolución". ${ }^{17}$

De este modo, la revista se proponía superar la vieja polémica entre los Grupos Florida y Boedo, abordando la literatura de Cortázar y Kafka. Asimismo, rescató el carácter crítico de las vanguardias, el psicoanálisis de Freud y el legado de José Ingenieros. Creada artesanalmente, indagó tanto en formatos como en el uso de recursos como la imagen, la ilustración y el diseño.

Por su parte, la revista Sitio, surgida en 1981, se propuso recuperar el "sitio" de las palabras, experimentando en sus posibilidades. Editada por Luis Gusmán, Jorge Jinkis, Ramón Alcalde, Eduardo Grüner y Hugo Savino, la revista insistía y rescataba la relevancia de la lectura, la cual:

"...quita al texto del lugar de víctima sacrificada por la interpretación de turno" y "tampoco indica alguna homogeneización de los discursos que se muestra capaz de engendrar". 18

\footnotetext{
${ }^{15}$ La noción de "Nueva Izquierda" alude a una serie de debates político-culturales que cuestionaron la línea ortodoxa del Partido Comunista luego de la revolución de Hungría en 1956, y que se manifestaron, en diversas partes del mundo, en el surgimiento de nuevos partidos y organizaciones guerrilleras, así como en iniciativas de intervención intelectual tales como revistas. Dichas discusiones fueron producto de la influencia de movimientos revolucionarios como los que se suscitaron en Cuba, Argelia y China. Para mayor información, véase Torti, María Cristina, "Izquierda y 'nueva izquierda' en la Argentina. El caso del Partido Comunista", disponible en: http://www.fuentesmemoria.fahce.unlp.edu.ar/art_revistas/pr.2814/pr.

${ }^{16}$ La revista, dirigida por Horacio Tarcus y Gabriel Vega, se fusionaba a partir de su número 3 con Nova Arte, dirigida por Enrique Záttara.

17 “Editorial: Justificación” en Revista Ulises $\mathrm{N}^{\circ}$ 0, abril de 1978, p. 3.

18 "Editorial: Localización” en Revista Sitio N³, agosto de 1983, pp. 3-4.
} 
Si bien varios de sus integrantes habían participado del proyecto editorial de Literal en la década de 1970, reconocían que la publicación no podía plantearse como heredera de su antecesora debido a las condiciones de publicación, circulación y recepción existentes. Con la lectura de figuras como Levi-Strauss, la revista se proponía recuperar el arte olvidado de escribir entre líneas, es decir, en el poder significante de las palabras. Se otorgaba así un lugar importante a la literatura, el psicoanálisis, poemas y ensayos. De esta manera, la referencia constante a "sitios", "lugares" y "localizaciones" remitía a recuperar el territorio de las palabras.

\section{Xuly Último Reino: el lugar de la poesía y las palabras}

Otra zona de publicaciones se encuentra conformada por revistas dedicadas a la poesía y la literatura. Es el caso de Último Reino, surgida en 1979, dirigida por Gustavo Margulies y Víctor Redondo; y Xul, surgida un año después y editada por Jorge Santiago Perednik. Ambas publicaciones presentaron rasgos en común como la existencia de jóvenes escritores y poetas en la formación de estos proyectos editoriales y la importancia asignada a la poesía como modalidad de expresión.

Último Reino se dedicó preferentemente a los poemas. Sólo pocos artículos en cada número podían incluir alguna reflexión, ilustración o documento, como la transcripción de un texto radiofónico o bien, algunos ensayos, como por ejemplo, sobre la joven poesía o textos de Maurice Blanchot, cuya distribución fue escasa y por eso se decidía su difusión desde la revista:

"Creemos necesario rescatar este texto pues en él se plantean cuestiones fundamentales para cualquier poeta, para reflexión sobre la poesía de su tiempo y sobre su propia obra. Y especialmente para nosotros, el grupo que se nuclea alrededor de esta revista que retoma (rei-inventa) los aspectos fundamentales del Romanticismo, sobre todo el alemán, que es uno de los ÚLTIMOS REINOS, y no obstante, se siente también vinculado a lo que Octavio Paz llamó la tradición de la ruptura." ${ }^{19}$

De esta manera, se planteaba la tensión entre ruptura y tradición. A su vez, otro rasgo particular de la revista consistió en que un espacio muy importante estaba dedicado a los poemas de jóvenes escritores como Horacio Jabaljáuregui y Roberto Scruglí así como poetas más reconocidos como el caso de Alfonso Sola González.

A diferencia de Último Reino, la revista Xul otorgó mayor lugar a las reflexiones y ensayos, además de la presencia de poemas. Laura Klein, integrante de Xul, reflexionaba sobre la diferencia entre ambas, centrada en que Último Reino, tenía mayor creencia y confianza en el lenguaje. El nombre de la publicación, Xul. Signo viejo y nuevo, rendía homenaje al poeta Edgar Maldonado Bayley y a la "dualidad implícita en el signo entre tradición y ruptura, entre institución y rebelión". ${ }^{20}$ Sus temáticas incluían, además de la difusión de poetas, reflexiones dedicadas a la poesía y literatura japonesa, la vanguardia, la propia existencia de la poesía argentina, la especificidad del lenguaje poético y la poesía concreta, entre otros temas. La revista dio lugar a jóvenes escritores y poetas como Néstor Perlongher, Leonardo Scolnik y Laura Klein. Ésta última reflexionaba retrospectivamente sobre las diferencias que existieron entre ambas publicaciones planteando que, en el caso de Último Reino y aunque siendo políticamente de izquierda, podían ser conservadores en la escritura:

19 "Maurice Blanchot: Reflexiones sobre la joven poesía” en Revista Último Reino N 1, octubre/diciembre de 1979.

20 "Editorial" en Revista Xul N 1, septiembre de 1980, pp. 1-2. 
“...además tenían confianza que la palabra noche significaba noche y yo creo que las palabras están vaciadas, entonces para decir amor tenés que decir cualquier otra cosa o lograr que se sienta algo. (...) teníamos como una pasión con la política de la escritura."21

Desde $X u l$, la discusión se centraba así en la posibilidad de una escritura que generara una ruptura con la idea de que las palabras significaran por sí mismas, proponiendo más bien la idea de que había que "torcerlas" de su orden cotidiano, indagando así en las posibilidades expresivas de la poesía.
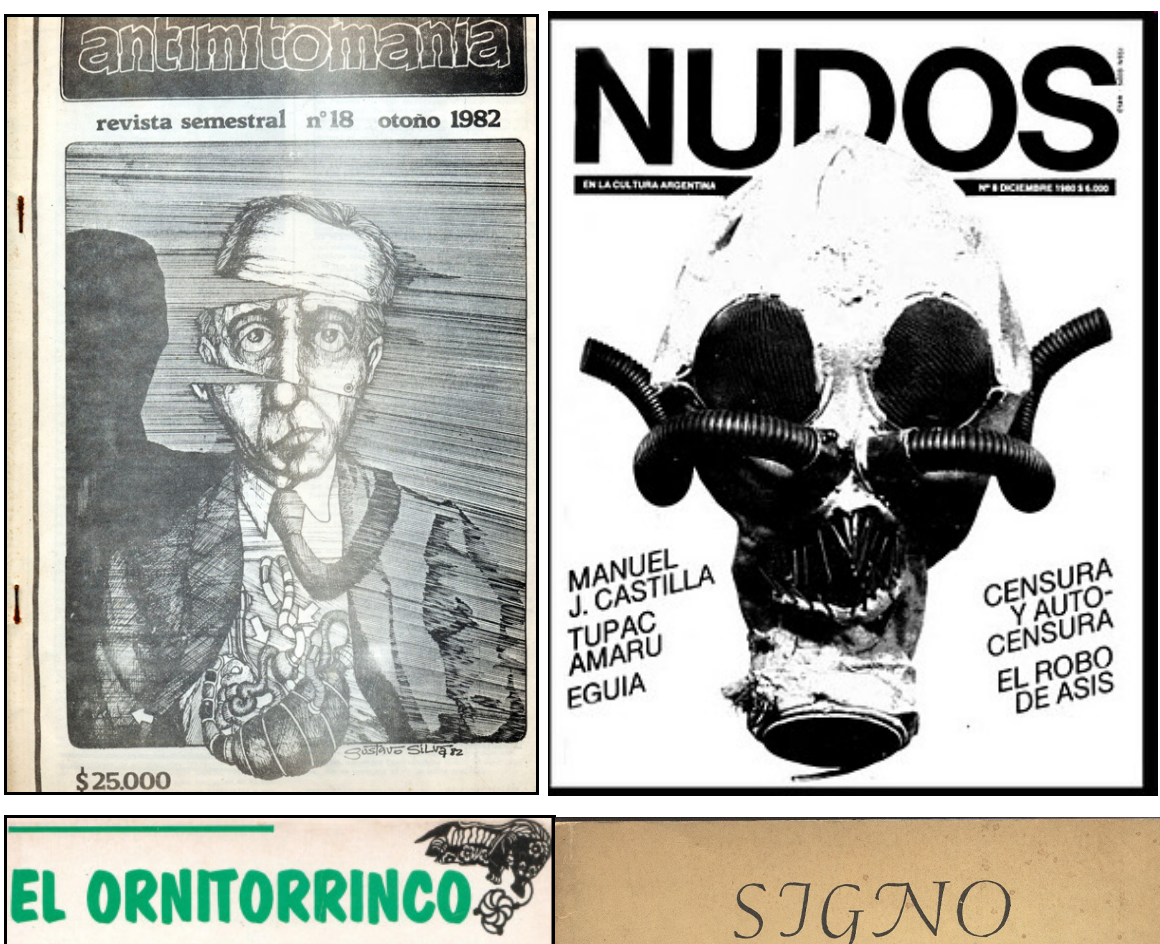

revista de literatura
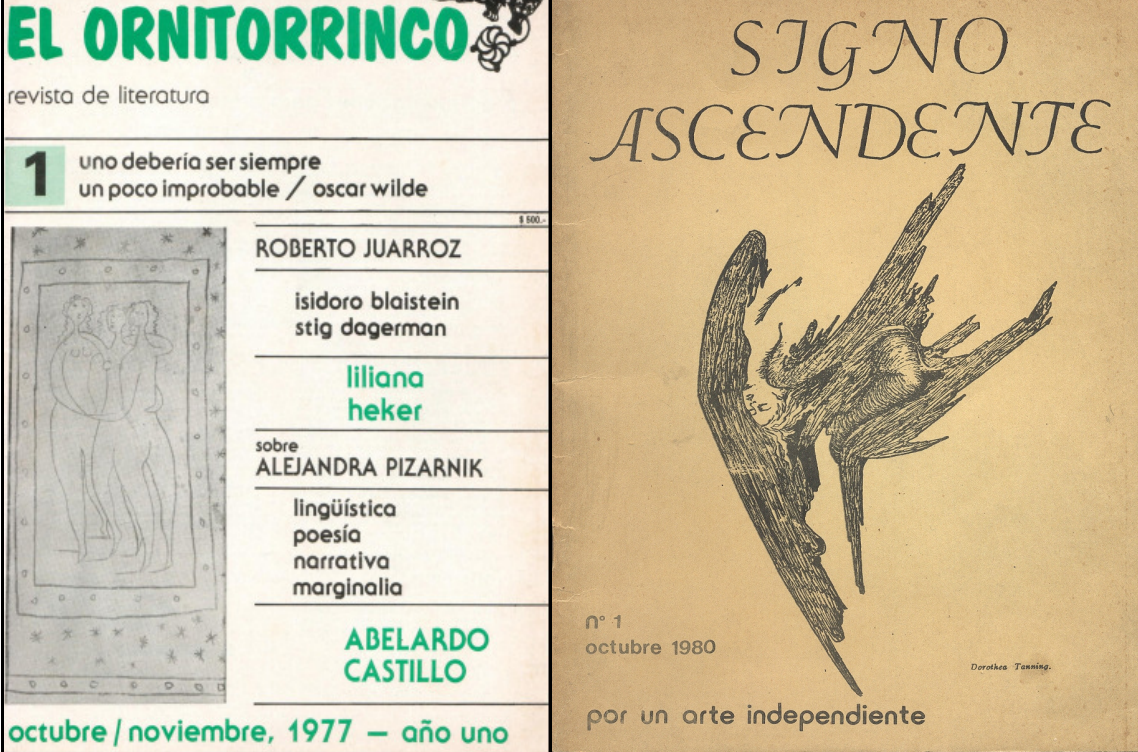

${ }^{21}$ Entrevista a Laura Klein, integrante de las Revistas Xul y Nova Arte, marzo de 2013. 


\section{La conformación de redes de publicaciones: diálogos y reconocimientos mutuos}

Una característica fundamental en estas revistas es que ellas conformaron espacios comunes de articulación de publicaciones, lo que permitió generar encuentros, discutir acerca de sus propias condiciones de existencia o subsistencia y coordinar una modalidad de intervención colectiva.

En 1979, surgía la Asociación de Revistas Culturales Argentina -ARCA- conformada por revistas como Nudos, Ulises, Cuadernos del Camino, Nova-Arte, El Ornitorrinco y Propuesta, entre otras; y la Asociación de Revistas Alternativas -ARA- en la que participaron revistas como Kosmos, Todos Juntos y Quijote. También el Grupo Alternativo de Trabajo Antimitomanía -GATA- conformado alrededor de la revista homónima.

La formación de estos colectivos de trabajo permitió crear redes de solidaridad y colaboración a partir de las cuales se organizaron encuentros de poesía, recitales, discusiones acerca de las condiciones de publicación de las revistas y la búsqueda de posturas comunes frente a la censura. Reunidas en lugares como La Casona de Iván Grondona de San Telmo o el Club Villa Malcolm de Palermo, los encuentros incluían desde lectura de poemas hasta declaraciones críticas respecto de la censura imperante.

Más allá de la heterogeneidad existente entre publicaciones en cuanto a criterios de diseño, periodicidad, modo de organización y tradiciones estético-políticas rescatadas, existió la autopercepción acerca de la pertenencia a un espacio común de revistas contraculturales. Por ello se reconocía la diferencia y contraposición existente respecto de una revista cultural como Pájaro de Fuego, que representó el canon de la cultura oficial y con la cual se polemizó.

Ulises reconocía este contrapunto entre dos casos: El Ornitorrinco -ubicada en el espacio de la cultura contestataria- y Pájaro de Fuego -ubicada en las antípodas-. A la vez, se identificaba con la postura de El Ornitorrinco, la cual propuso una mirada diferente a la de la cultura oficial:

"En el último trimestre, dos de las revistas más importantes del quehacer cultural -El Ornitorrinco $\left(\mathrm{N}^{\circ} 4\right)$ y Pájaro de Fuego $\left(\mathrm{N}^{\circ} 8\right)$ - dedicaron sus editoriales al litigio del Beagle. (...) Ulises saluda entusiastamente a las vigorosas palabras de Abelardo Castillo y se identifica plenamente con ellas. 'Hay que comprometerse -dice Castillo-. La guerra mata con la estupidez ciega de la peste o los tifones, peor, porque es un cataclismo organizado'. Por sobre todos los territorios están quienes los habitan, quienes pueden morir por la insensatez de unos pocos. La defensa del ser, sin distinción de nacionalidades y geografía, es lo que prima para El Ornitorrinco. Por el contrario, nos alarma la Editorial firmada por Carlos Garramuño ${ }^{22}$.(...) 'El Pájaro...' evita nombrar responsables y lo que es mucho peor, apoya una 'actitud' que recae sobre dos poblaciones seriamente amenazadas por una gran irresponsabilidad". ${ }^{23}$

La perspectiva propuesta a partir del conflicto con Chile por el Canal de Beagle fue muy distinta en estas dos publicaciones y de esta manera, El Ornitorrinco advertía acerca de lo insensato de una posible guerra, muy diferente de la mirada oficial. Asimismo, resulta relevante observar la relación de colaboración y solidaridad establecida entre las distintas revistas alternativas a partir de sus diálogos, reconocimientos y referencias mutuas. A modo de ejemplo, El Ornitorrinco publicaba una nota en la que celebraba el surgimiento de la revista Nova-Arte como una muestra del dinamismo que adquiría el campo cultural:

\footnotetext{
22 Miembro de la Revista Pájaro de Fuego.

${ }^{23}$ Vega, Gabriel y Tarcus, Horacio, "Dos editoriales" en Revista Ulises N 1, diciembre de 1978, p. 34.
} 
"Estas revistas remueven el clima cultural de un país mostrando de paso que quienes especulaban con un supuesto aquietamiento del impulso creador entre nosotros se equivocan". ${ }^{24}$

Por su parte, Ulises reconocía la existencia de un universo de revistas que conformaban la cultura underground. La posibilidad participar de estas redes implicó generar pertenencias a partir de tramas colaborativas colectivas:

"El Ornitorrinco, Oeste, Nudos, Ayesha, Nova-arte, Cuadernos del Camino, Gog y Magog, Propuesta, Periscopio, etc., etc. Desde la cultura oficial que representa Pájaro de Fuego hacia la cultura under de las autodenominadas revistas subterráneas de los rockeros y afines, se extiende un espectro sorprendente de revistas literarias y de cultura en general que inundan quioscos y librerías o que se distribuyen de mano en mano". ${ }^{25}$

La existencia de este un frente antidictatorial, en términos de sus protagonistas, posibilitó romper el aislamiento. Debido a los mecanismos represivos y a la presencia de un poder "desaparecedor" ${ }^{\text {, }}$, no podemos plantear que las experiencias que analizamos se hayan presentado como una propuesta contrahegemónica al poder. Sin embargo y aunque imposibilitadas de disputarlo, desafiaron sus límites tomando como punto de partida la palabra, la cual permitió verbalizar, esto es, nombrar aquello que sucedía. Así aparecía en la editorial de la revista Cuadernos del Camino:

"Resumiendo: lo que nos parece intolerable es que, a esta altura del siglo, todavía existan seres mesiánicos que se arroguen el derecho de determinar qué es lo que el público puede consumir y lo que el artista y el científico pueden crear."27

De esta manera, se tomaba como principal oponente y objeto de polémica, al régimen militar y sus dispositivos de censura. La experiencia de estas publicaciones implicó la conformación de un frente cultural que resistía y confrontaba con la política cultural oficial.

\section{Los primeros años de la postdictadura}

Durante los primeros años de la denominada "transición democrática" argentina, se produjeron cambios al interior del campo de las revistas culturales. Por un lado, se retomaron ciertas discusiones postergadas acerca del vínculo entre cultura y política que se había generado durante la década de 1970 y el período dictatorial. Surgió entonces la necesidad de realizar un balance retrospectivo que permitiera analizar el pasado reciente:

"Había una crítica muy fuerte a la experiencia setentista, a veces muy reduccionista, muy simplificada producto de la época también porque la gente se tenía que exorcizar. (...) Era la necesidad de reinventar un pasado, si vos lo miras analíticamente ¿cómo se reinventaba una democracia después de una extraordinaria derrota?". ${ }^{28}$

Si bien no pretendemos agotar las diferentes discusiones entabladas a partir del retorno a las instituciones democráticas en el contexto de la denominada "transición", ${ }^{29}$ nos interesa dejar

\footnotetext{
24 “Bibliográficas" en Revista El Ornitorrinco $\mathrm{N}^{\circ}$ 5, enero/febrero de 1979, p. 26.

25 "Salpicón Cultural: Encuentro Nacional de Revistas Literarias" en Revista Ulises N 1, diciembre de 1978, p. 35.

${ }^{26}$ Calveiro, Pilar, Poder y desaparición. Buenos Aires, Colihue, 1998.

27 "Editorial" en: Revista Cuadernos del Camino N 2, marzo de 1979, p. 1.

${ }^{28}$ Entrevista a Lucas Rubinich, integrante de la Revista Pie de Página, julio de 2012.

${ }^{29}$ Cecilia Lesgart repone una serie de debates acerca de la idea de "transición democrática”. Para mayor información, véase: Lesgart, Cecilia, “Ciencia política y producción de la idea de Transición a la democracia. La reorganización de
} 
planteada la nueva dinámica que asumió el campo cultural e intelectual, a partir de la necesidad que surgió de retomar el pasado para otorgar nuevas claves de lectura e interpretativas sobre aquello que se había vivido en los años anteriores. De esa manera, salieron a la luz nuevas discusiones acerca del vínculo entre intelectuales, cultura y política. Por un lado, se intentaba "reinventar" la idea de democracia y discutir acerca del retorno a la institucionalidad. Por otro lado, ello implicaba revisar el pasado reciente y debatir acerca de la "derrota" experimentada en los movimientos sociales y políticos de la década anterior.

En el campo del periodismo cultural, esa necesidad de retomar la discusión implicó que las diferencias entre publicaciones se hicieran paulatinamente más evidentes. Si durante la dictadura, se produjo un "frente cultural antidictatorial" que implicó dejar de lado ciertas polémicas, ellas necesariamente llegaron durante la "transición democrática". Fue así como la idea de frente se rompió y afloraron las diferencias estéticas y políticas entre publicaciones. ${ }^{30}$ Asimismo, ciertas temáticas que sólo tuvieron un lugar preponderante en publicaciones contraculturales durante la dictadura, comenzaron a tener espacio en otros ámbitos públicos. Por lo tanto, muchas revistas experimentaron transformaciones a partir de que los grupos culturales que le dieron origen, se volcaron a otros ámbitos de intervención.

\section{Algunas conclusiones}

A partir de lo desarrollado, resulta relevante considerar algunos ejes de análisis e interpretación. Por un lado, nos interesa retomar la idea que aparece en varias publicaciones de que el campo de las revistas contraculturales durante la dictadura implicó la posibilidad de llenar un vacío y cubrir una necesidad vital. La existencia de estas publicaciones dio lugar a que ciertas temáticas, ausentes en otros espacios del campo de la producción cultural debido a los mecanismos represivos y de control, se hicieran visibles en esta zona del campo simbólico. Numerosos tópicos de discusión, tales como la denuncia a la censura, la crítica a la postura belicista del régimen, los reclamos de los organismos de Derechos Humanos y la contraposición con la política cultural oficial, encontraron su lugar en estas publicaciones. Por lo tanto, observamos en este tipo de experiencias un gran dinamismo que permitió reponer una serie de discusiones que se dieron muy tempranamente en estas publicaciones y que posteriormente se expandirían hacia otros ámbitos públicos.

En segundo lugar, es importante rescatar un elemento común en estas revistas durante el período de la dictadura, relacionado con la idea de "prueba", es decir, de ensayos acerca de hasta dónde fue posible experimentar a través de las palabras y los recursos gráficos. Esto implicó “jugar” con los márgenes existentes entre lo deseable y lo realizable, entre la necesidad de expresión y las reales condiciones de posibilidad. En este sentido, se puso en juego la idea de "probar" hasta dónde se permitía experimentar con los límites - difusos y variables- y de qué manera podían ser alterados a lo largo del tiempo. Por lo tanto, la escritura fue comprendida como un lugar de intervención a partir del lenguaje de la retórica plasmado en figuras como la elipsis, la metáfora o la alegoría.

Por último, nos interesa plantear que, si bien las publicaciones subterráneas o alternativas no se presentaron como un proyecto de oposición o contrahegemónico, ellas desafiaron los mecanismos de censura impuestos por el poder militar. En este aspecto, es necesario reconocer la

un campo del conocimiento" en Fernández, Arturo (comp.), La ciencia política en la Argentina. Dos siglos de historia. Buenos Aires, Biebel, 2002.

${ }^{30}$ Warley, Jorge, "Revistas culturales de dos décadas (1970-1990)" en Cuadernos Hispanoamericanos $\mathrm{N}^{\circ}$ 517-519, juliosetiembre de 1993, pp. 195-207. 
diversidad de publicaciones y visualizar sus desplazamientos a lo largo del período dictatorial, así como destacar que su posicionamiento no significa pensar estas prácticas en forma homogénea sino observando sus diferentes modos de "disidencia". Sin embargo, es importante señalar que, en estas experiencias -diversas y multiformes-, la intervención cultural fue un modo de despliegue de tácticas que cobraron una dimensión política al intentar ejercer presiones y alterar, aunque fuera en algún aspecto, los dispositivos de disciplinamiento del poder. Tales tácticas consistieron, entre otros elementos, en construir redes colectivas y espacios comunes, cuestionar los cánones de la cultura oficial, denunciar la represión y abordar "otras" temáticas. De esta manera, la esfera de lo simbólico fue concebida como un espacio estratégico para la intervención política.

\section{Bibliografía}

Águila, Gabriela, Dictadura, represión y sociedad en Rosario, 1976/1983, Buenos Aires, Prometeo, 2008.

Bourdieu, Pierre, Sociología y cultura, México, Grijalbo, 1990.

Calveiro, Pilar, Poder y desaparición, Buenos Aires, Colihue, 1998.

Iglesias, Federico, "Vale más revista literaria en mano que escritor volando: El Ornitorrinco y el rol de los escritores durante la última dictadura cívico militar argentina, 1976-1983", ponencia ante las Terceras Jornadas de Investigación del AGU, Montevideo, Uruguay, 2013.

Jelin, Elizabeth y Longoni, Ana, Escrituras, imágenes, escenarios ante la represión, Madrid, Siglo XXI, 2004.

Lesgart, Cecilia, "Ciencia política y producción de la idea de Transición a la democracia. La reorganización de un campo del conocimiento", en Fernández, Arturo (comp.), La ciencia política en la Argentina. Dos siglos de historia, Buenos Aires, Biebel, 2002.

Marcus, Cecily, "En la Biblioteca Vaginal: un Discurso Amoroso" en: Politicas de la Memoria $\mathrm{N}^{\circ}$ 6/7, CeDInCI, Primavera 2006-2007.

Marcus, Cecily, "Las revistas culturales subterráneas en la dictadura", ponencia ante las II Jornadas de Historia de las Irquierdas, Buenos Aires, CeDInCI, 2002.

Simpson Grinberg, Máximo, Comunicación alternativa y cambio social, México, Premia, 1986.

Warley, Jorge, "Revistas culturales de dos décadas (1970-1990)" en: Cuadernos Hispanoamericanos $\mathrm{N}^{\circ}$ 517-519, Julio-setiembre de 1993, págs. 195-207.

Williams, Raymond, Cultura. Sociología de la Comunicación y del Arte, Barcelona, Paidós, 1994.

Williams, Raymond, Marxismo y Literatura, Barcelona, Península, 1988. 